\title{
PACK FACTOR MEASUREMENTS FOR CORN IN GRAIN STORAGE BINS
}

\author{
R. Bhadra, A. P. Turner, M. E. Casada, M. D. Montross, S. A. Thompson, \\ J. M. Boac, S. G. McNeill, R. G. Maghirang
}

\begin{abstract}
Shelled yellow corn is commonly stored in concrete or corrugated steel bins. Granular materials compact under their own weight, primarily due to particle rearrangement, leading to an increase in bulk density and a change in volume when stored. Reliable grain pack factors are needed to estimate storage capacities and to accurately monitor grain inventories. A science-based model (WPACKING) of pack factors is available that uses the differential form of Janssen's equation and takes into account the variation in density caused by pressure variation with height and moisture content of the grain and accounts for the effects of grain type, test weight, bin geometry, and bin material. However, this model needs to be compared to field data over a wide range of conditions to ensure robust prediction accuracy. The objective of this research was to determine the field pack factors and bin capacities for on-farm and commercial bins used to store corn in the U.S. and compare them to predictions of the WPACKING program. Bin inventory measurements were conducted in concrete bins with depths up to $31.4 \mathrm{~m}$ (114.8 ft) and corrugated steel bins with diameters up to $32.8 \mathrm{~m}$ $(156 \mathrm{ft}$ ). These values were also compared to the techniques used by the USDA Risk Management Agency (RMA) and the USDA Farm Service Agency, Warehouse Branch (FSA-W). The differences between predicted and reported mass were $4.54 \%$ (maximum underprediction) to $+4.53 \%$ (maximum overprediction) for WPACKING, $-2.69 \%$ to $4.97 \%$ for the RMA method, and $-3.33 \%$ to $+5.67 \%$ for the FSA-W method. The absolute average difference was lowest for the WPACKING model $(0.90 \%)$ compared to the RMA and FSA-W methods (1.61\% and $1.86 \%$, respectively). WPACKING had less than half as many prediction differences above 1\% (13 out of 51 bins) as did the RMA and FSA-W methods, which had 29 out of 51 and 33 out of 51, respectively. The RMA and FSA-W methods do not take into account the variations in pack factor due to bin type and moisture content of the stored grain.
\end{abstract}

Keywords. Commercial bin measurement, Corn, FSA, Laser distance meter, RMA, Steel and concrete bins, Stored grain pack factor, WPACKING.

Submitted for review in October 2014 as manuscript number PRS 11033; approved for publication by the Processing Systems Community of ASABE in April 2015.

The research was supported by the USDA (CRIS No. 5430-43440007-00D) and by the Kansas Agricultural Experiment Station (Contribution No. 15-404-J).

Mention of trade names or commercial products in this publication is solely for the purpose of providing specific information and does not imply recommendation or endorsement by the USDA. The USDA is an equal opportunity provider and employer.

The authors are Rumela Bhadra, ASABE Member, Research Associate, Department of Biological and Agricultural Engineering, Kansas State University, Manhattan, Kansas; Aaron P. Turner, Agricultural Engineer, University of Kentucky, Lexington, Kentucky; Mark E. Casada, ASABE Member, Research Agricultural Engineer, USDA-ARS Center for Grain and Animal Health Research (CGAHR), Manhattan, Kansas; Michael D. Montross, ASABE Member, Professor, Department of Biosystems and Agricultural Engineering, University of Kentucky, Lexington, Kentucky; Sidney A. Thompson, ASABE Member, Professor, College of Engineering, University of Georgia, Athens, Georgia; Josephine M. Boac, ASABE Member, Research Associate, Department of Biological and Agricultural Engineering, Kansas State University, Manhattan, Kansas; Samuel G. McNeill, ASABE Member, Associate Extension Professor, Department of Biosystems and Agricultural Engineering, University of Kentucky, Princeton, Kentucky; and Ronaldo G. Maghirang, ASABE Member, Professor, Department of Biological and Agricultural Engineering, Kansas State University, Manhattan, Kansas. Corresponding author: Mark Casada, USDA-ARS CGAHR, 1515 College Ave., Manhattan, KS 66502; phone: 785-7762758; e-mail: mark.casada@ars.usda.gov.

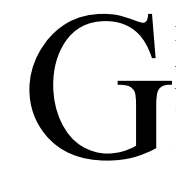

rain stored in bins is subjected to packing from pressure caused by the overlying grain mass. Grain packing in bins is defined as the increase in grain bulk density caused by compression from the cumulative weight of the overlying grain material. Because this compression causes relatively large increases in bulk density, accurate pack factors that account for the increase are required for determining the exact amount of grain in a bin. While grain is traded on a mass basis, the vast majority of grain inventory and auditing assessments are based on volume measurements. Accurate pack factors are needed by grain elevator managers and farmers for proper inventory control, and by government agencies for auditing. Because of persistent questions about the accuracy of pack factors currently in use, the USDA Risk Management Agency (RMA) requested work to develop new, more accurate pack factors, which led to the study reported here.

It is often difficult to predict how grain will compact because bulk grain consists of a complex matrix of irregularly shaped particles, each with its own characteristics. Thus, most bulk grain packing prediction models have been done empirically (Thompson et al., 1991). In powder technology, there is extensive literature on particle packing (Smalley, 1970). Although Smalley (1970) provided a packing theory 
commonly used to describe the packing of fine powders with very regular shape and size geometry, it failed to address the situation with whole grains, where the particles are of random shape and size and are compressible.

Particle packing in whole grains is believed to vary as a function of the stress variation that exists within a given material type, moisture content, and uncompressed bulk density of the material. To understand the phenomenon of grain packing, it is essential to consider the variation in bulk particle properties (such as density changes, moisture changes, compressibility, flow rate, etc.) when stored in bins. While the geometry of a bin can be measured accurately, measuring the variation in bulk material properties of the grain inside the bin can be challenging (Thompson et al., 1987). Bates (1925) was first to research packing of granular materials in storage silos containing wheat, and he proposed that the average packing of wheat was $4.85 \%$. Bates (1925) included dimension of the bin, shape, test weight, and depth of grain in the packing of wheat calculation.

The classic theory provided by Janssen (1895) for predicting pressure in grain bins given in differential form is:

$$
\frac{d P}{d y}=g D-\frac{k P \mu}{R}
$$

This equation was solved by Janssen after simplifying assumptions of constant bulk density $(D)$, lateral to vertical pressure ratio $(k)$, and coefficient of friction $(\mu)$, giving:

$$
P_{j}=\frac{w R}{\mu k}\left[1-\exp -\left(\frac{\mu k y}{R}\right)\right]
$$

where $P_{j}$ is the unit vertical pressure at depth $y, w$ is the constant bulk density of the granular material, $R$ is the hydraulic radius (bin cross-sectional area divided by circumference), $\mu$ is the coefficient of friction between stored material and the bin wall, $k$ is the ratio of lateral to vertical pressure at any point, and $y$ is the depth of grain measured from the top of the grain to the grain section under consideration. The assumption that $w$ and $k$ are constants has been found to be untrue. For example, bulk density in corn meal was found to be related to vertical pressure with a parabolic relationship with $\mathrm{R}^{2}$ of 0.94 by Clower et al. (1973), and $k$ was found to vary from 0.3 to 0.67 for wheat samples tested by Amundson (1945) and Lorenzen (1957). Furthermore, $k$ values for wheat, soybean meal, and sugar beet pulp varied most at pressures below $14 \mathrm{kPa}$ (2 psi) and varied little at higher pressure levels (Clower et al., 1973). Loewer et al. (1977) found that bulk density varied with the moisture content of granular materials in addition to varying with vertical pressure, and $k$ varied with moisture content. Finally, Thompson et al. (1990) provided correlations of predicted density with uncompressed density, pressure, and moisture as required to predict density and packing in storage bins based on predicted pressures in the bins.

McNeill et al. (2008) measured changes in bulk density and found pack factors of $7.6 \%$ to $11.6 \%$ for corn meal, $4.3 \%$ to $6.8 \%$ for cracked corn, and $5.1 \%$ to $8.2 \%$ for soybean meal with pressures from 0 to $69 \mathrm{kPa}$ (0 to $10 \mathrm{psi}$ ), which is typical for pressures in grain storage bins. Studies have been conducted on how grain spreaders can change the bulk density, airflow resistance, and frictional properties of granular materials (Chang et al., 1983; Stephens and Foster, 1976; Moysey, 1984). For yellow corn in grain bins, Chang et al. (1983) found that bulk density increase was between $5.8 \%$ and $9.6 \%$ when any kind of spreaders were used. Other studies characterized the effects of bin filling methods, such as four spout, sprinkle, and uniform filling techniques (Molenda et al., 1993), on change in bulk densities. These results showed that bulk densities were affected significantly by loading method.

Methods to determine pack factors for on-farm and commercial elevator bins include those used by two governmental agencies: the USDA Farm Service Agency, Warehouse Branch (FSA-W) and the RMA. The FSA-W used an empirical approach to tabulate the values of pack factors for six whole grains based on initial test weight (TW) and moisture content, as given in the Warehouse Examiner's Handbook (USDA, 2008). The RMA loss adjustment handbook and manuals (USDA, 2011, 2012) provide empirically based tabular values for pack factor for seven whole grains. Both methods provide pack factors based on empirical data taken from bins with little variation in size. Neither of these techniques takes into account the effect of grain depth or variation in the stored grain properties on pack factor. A science-based model (based on grain pressure distribution from eq. 1) to predict pack factor was provided by Thompson et al. (1987). To date, there has been limited field validation of the WPACKING model.

\section{DEVELOPMENT OF WPACKING}

The pack factor prediction model, WPACKING, is based on the differential form of Janssen's (1895) equation (eq. 1), which predicts pressure in grain bins at a particular grain height. While Janssen's solution had a major drawback, i.e., the bulk density was assumed constant throughout the grain column, WPACKING solves the differential equation without invoking this simplifying assumption, which allows the varying bulk density to be calculated based on the predicted pressure and laboratory measurements of compressibility. Thompson et al. (1987) measured bulk density as a function of pressure and moisture content for several crops (soft red winter wheat, sorghum, corn, soybeans, rice, and hard red winter wheat), including several varieties for each crop. They combined nonlinear models for bulk density of these crops within WPACKING to predict pack factors and estimate standard bushels in a bin based on user inputs for grain as well as bin dimensions and properties. Eventually, the work of Thompson et al. $(1987,1990)$ led to the development of ASABE Standard EP413.2 (ASABE, 2010).

The objective of this study was to determine the pack factor of corn in on-farm and commercial storage bins with varying bin shape and size and with a typical range of moisture content and initial test weight. A wide range of geographic locations was included to increase the robustness of the dataset. Pack factors and grain mass values for the bins predicted using WPACKING were compared with the measured mass of grain in storage bins. These predic- 
tions were also compared to the predictions of the two current U.S. government agency methods of pack factor predictions: the RMA and FSA-W methods.

\section{Materials ANd Methods \\ Field MEASUREMENTS AND DATA COLleCtion}

The field data reported in this article were collected from on-farm and commercial corn bins measured from 2011 to 2013. Elevator cooperators and individual farmers provided data on grain material properties (test weight and moisture content) and empty bin geometry. The bin diameter, eave height (side wall height of the bin), plenum height (for adjusting eave height), angle of the roof if needed, bin wall material (smooth steel, corrugated steel, or concrete), and hopper bottom angle (for hopper bottom bins) were measured using a Leica Disto D8 laser distance and angle meter (Leica Geosystems AG, St. Gallen, Switzerland). Some measurements were taken with conventional tape measures as needed.

Pack factors were calculated using the WPACKING, RMA, and FSA-W methods to determine the predicted mass of stored corn based on the measured volume. The WPACKING program estimated pack factor $\left(R_{W}\right)$ using a solution to the differential form of Janssen's equation for pressure and based on user inputs for bin wall material, bin geometry, and grain properties (Thompson et al., 1990). Values of $\mu$ and $k$ used in the model are specified in ASABE Standard EP413.2 (ASABE, 2010). The USDA-RMA specifies tabular values of pack factors for seven U.S. crops (including corn) based on grain TW and bin cross-sectional area (USDA, 2011, 2012). These tabular values were used to determine the RMA pack factor $\left(R_{R}\right)$. Similarly, pack factors for the FSA-W method $\left(R_{F}\right)$ were from tables used by the USDA-FSA (USDA, 2008). Masses were calculated by all three methods, giving WPACKING-predicted mass, RMA-predicted mass, and FSA-W-predicted mass, which were compared to the reported mass from the stored grain manager. Further details on measurement methods and calculation of pack factors for these three methods can be found in Boac et al. (2015).

\section{Field Measurements of Individual Bins}

Multiple points on the grain surface were measured with the laser meter to describe the grain profile and determine the cone angle of the stored grain. The laser meter was mounted on a tripod that allowed the laser to sweep from the top of the cone to the bottom of the cone, where the grain touches the bin wall. About seven equally spaced points on the nearest grain surface of the cone were chosen, and the laser device determined the distance and angle from the reference point on the tripod for each of these points. From these seven points along the cone, the cone angle was determined for the grain pile. In an undisturbed pile, this cone angle would be expected to match the angle of repose of the grain (Mohsenin, 1986); however, in this study, the cone angle was measured for every bin, and no assumptions were made regarding these angles. The stored grain manager provided the reported mass and the average TW, foreign material (\%), damage (\%), and moisture content (\% w.b.) by individual bin. Grain mass is commonly reported as standard bushels in the U.S. grain industry, where a standard bushel of corn is equivalent to $56 \mathrm{lbs}$ at $15.5 \%$ (w.b.) moisture content for No. 2 shelled corn per USDA guidelines. However, for this study, we always obtained the reported grain mass directly in pounds (lbs). The measured volume was used with the reported TW to calculate the predicted pack factors based on the WPACKING, RMA, and FSA-W methods. To determine the predicted mass of grain in the bin, the measured grain volume was multiplied by the predicted pack factors from the three methods, as described below.

The mass of grain in a bin can be calculated from the measured volume of grain using:

$$
M=D_{S} \cdot R \cdot V
$$

where

$M=$ mass of grain in the bin ( $\mathrm{t}$ or lbs)

$V=$ measured volume of grain in the bin $\left(\mathrm{m}^{3}\right.$ or volumetric bu)

$R=$ pack factor including test weight (from one of the three methods)

$D_{S}=$ standard bulk density (standard test weight) of the grain $\left(\mathrm{kg} \mathrm{m}^{-3}\right.$ or $\left.\mathrm{lbs} \mathrm{bu}^{-1}\right)$.

$R$ is related to the compaction factor as:

$$
f_{c}=R \cdot\left(\frac{D_{S}}{D_{0}}\right)-1
$$

where $D_{0}$ is the initial bulk density, or uncompacted test weight, of the grain from the Winchester bushel test $\left(\mathrm{kg} \mathrm{m}^{-3}\right.$ or $\left.\mathrm{lbs} \mathrm{bu}^{-1}\right)$, and $f_{c}$ is the compaction factor of the grain. The compaction factor $\left(f_{c}\right)$ is defined as the reduction in volume of stored grain due to compaction (usually expressed as a percentage), and this term was used in ASABE Standard EP413.2 (ASABE, 2010). Details of related pack factor relationships can be found in Boac et al. (2015).

For the 51 individual bins, the reported mass of grain from scale measurements was available for each bin from the grain elevators or farmers, along with other crop quality parameters. In those cases, the predicted mass for each bin was compared to the reported mass for that bin.

\section{Field Measurement of Grouped Bins}

Stored grain managers provided the total mass of corn at the facility and the estimated moisture content and test weight of the corn. At facilities with bins grouped for analysis, the volume of each bin was measured using additional points on the grain surface with the laser meter when necessary to accurately define the surface. Based on the bin dimensions, TW, and volume measurement, the pack factor for each bin was determined using the WPACKING, RMA, and FSA-W methods. The total mass of stored corn was predicted and compared to the reported mass. There were 37 bins at facilities where collaborators only reported total mass for all the bins at the facility.

\section{Summary of Field Data Collection}

Table 1 summarizes the on-farm and commercial bins that were analyzed individually, primarily in the Midwest, 
Table 1. Crop quality, bin geometry, and pack factors for individually reported corn bins. ${ }^{[a]}$

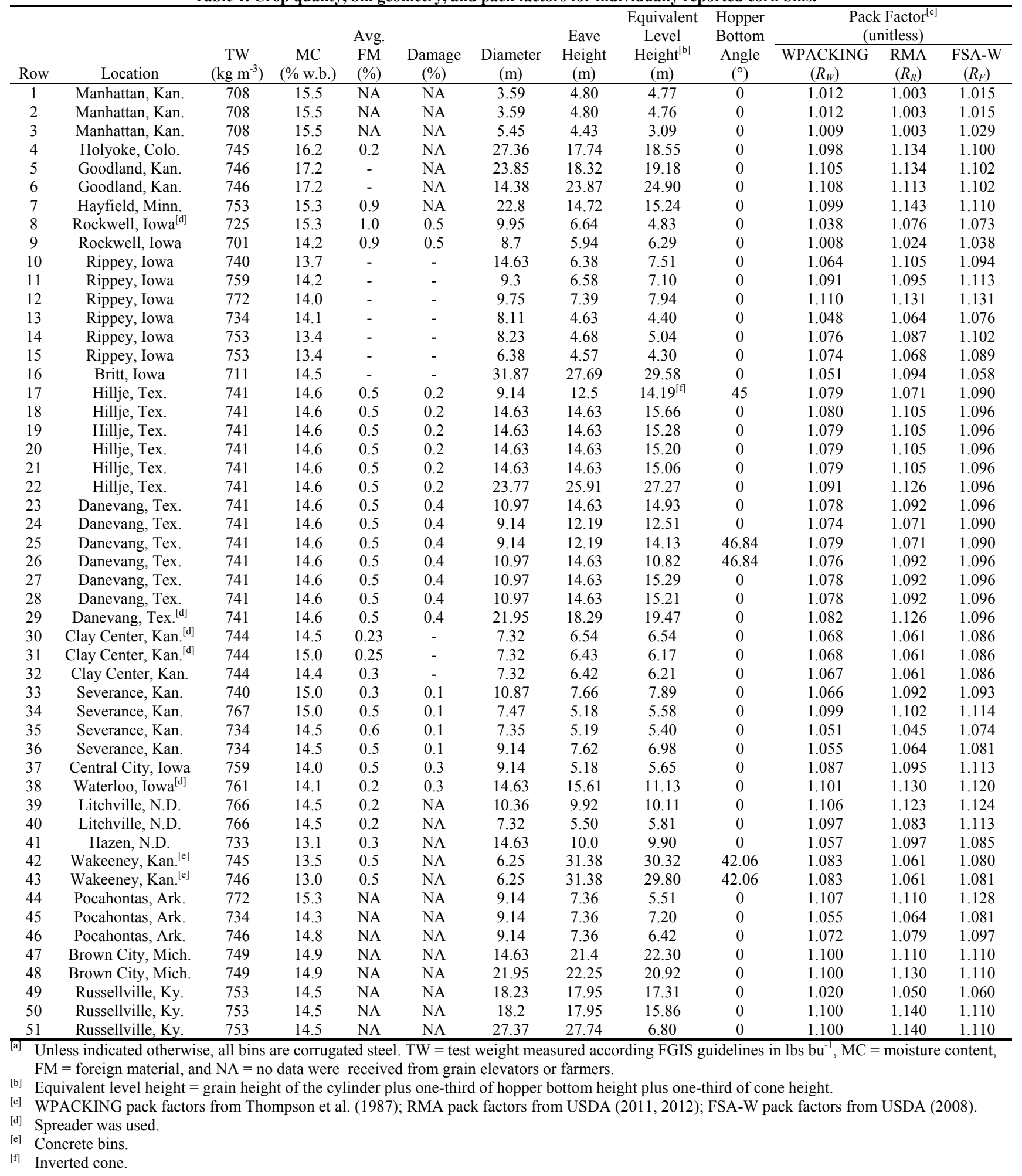

Central, and South Central regions of the U.S. (Arkansas, Kansas, Colorado, Minnesota, Michigan, Iowa, Kentucky, Texas, and North Dakota). Other than two concrete bins in Wakeeney, Kansas (rows 42 and 43), all the bins were constructed of corrugated steel. This highlights a recent shift in the grain industry in which large steel bins are commonly used rather than concrete bins. All bins were center filled.

The cylinder height is defined as the distance between the bottom of the sidewall (where the hopper section begins) and the points on the side wall where the grain surface touches the wall. It is calculated by subtracting the airspace at the sidewall from the entire eave height. However, for the two bins (rows 25 and 26) that had hopper bottoms with an angle of $46.8^{\circ}$, the effective eave heights for those bins would be eave height plus one-third of the

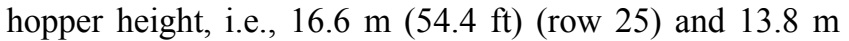


(45.3 ft) (row 26). Additionally, two concrete bins (rows 42 and 43) had offset hopper bottoms (angle of $42.0^{\circ}$ ) instead of regular hopper bottoms, but the effective eave height was still eave height plus one-third of hopper height, i.e., $33.26 \mathrm{~m}(109.1 \mathrm{ft})$ for rows 42 and 43 . The offset hopper bottoms were oblique circular cones with one vertical edge in which the grain discharge orifice was located. Regular hopper bottoms were right circular cones with the grain discharge orifice located in the center. Hopper bottom angles of more than $37^{\circ}$ are desirable for the free flow of grain from the bin (MWPS, 1997).

When grain is loaded into a bin, it forms a cone-shaped pile. The angle of repose is the angle of the cone relative to the horizontal plane of the piled grain (Mohsenin, 1986). The cones in some of the bins measured in this study were not at the natural angle of repose (i.e., they were outside the range of literature values for angle of repose of corn, e.g., $16^{\circ}$ for filling angle of repose; Stahl, 1950) and had a lesser angle caused by partial unloading of grain, disturbance of the top surface by workers, or variations in the filling method. It was difficult to determine what variables occurred within each bin to influence the grain surface and alter the natural angle of repose; therefore, we use the term "cone angle" in this article. The cone angle ranged from $1.9^{\circ}$ to $30.2^{\circ}$, with a median value of $20.4^{\circ}$. Smaller angles obviously represent surfaces affected by unloading, filling method, or disturbance. After a bin is partially emptied, an inverted cone may exist at the surface. The single case with an inverted cone angle is indicated with a footnote in table 1. Equivalent level height was defined as total grain height, which was the sum of equivalent cone height (onethird of cone height to the peak), cylinder height where grain is parallel to the bin wall, and equivalent hopper height (one-third of total hopper height).

\section{RESULTS AND DISCUSSION}

The average TW (average of all the TW values from individual truck loads that went into each bin) ranged from $701 \mathrm{~kg} \mathrm{~m}^{-3}\left(54.5 \mathrm{lbs} \mathrm{bu}^{-1}\right)$ to $772 \mathrm{~kg} \mathrm{~m}^{-3}\left(60.0 \mathrm{lbs} \mathrm{bu}^{-1}\right)$, with a median TW of $741 \mathrm{~kg} \mathrm{~m}^{-3}\left(57.6 \mathrm{lbs} \mathrm{bu}^{-1}\right)$. Moisture contents ranged from $13.0 \%$ to $17.2 \%$ (w.b.), with a median of $14.6 \%$ (w.b.). Foreign material (FM) ranged from $0.21 \%$ to $1.00 \%$, with a median of $0.50 \%$. These material properties for corn were within the normal ranges for corn found in the U.S. Table 1 also provides details about grain characteristics and pack factors. Normally, if a spreader is used, the grain pile will be much flatter with no cone angle, and this was confirmed for the facilities with spreaders. For example, the steel bin at Rockwell, Iowa (row 8) used a spreader to flatten the grain pile inside the bin, and the cone angle is zero (row 8). Table 1 indicates that bin diameters ranged from 3.59 (11.8 ft) to $31.87 \mathrm{~m}(104.5 \mathrm{ft}$ ) (median of $9.30 \mathrm{~m}$, $30.5 \mathrm{ft})$, and eave heights ranged from $4.43(14.5 \mathrm{ft})$ to $31.4 \mathrm{~m}(102.9 \mathrm{ft})$ (median of $10.0 \mathrm{~m}, 32.8 \mathrm{ft}$ ).

The TW values found in this study (702 to $772 \mathrm{~kg} \mathrm{~m}^{-3}$, with a median of $741 \mathrm{~kg} \mathrm{~m}^{-3}$; table 1) were within the range commonly found for shelled corn (No. 2) in the U.S., measured using Federal Grain Inspection Service (FGIS) guidelines and a Winchester bushel cup (USDA, 2013). Other corn quality parameters (moisture content, FM, and damage) were determined by FGIS guidelines for corn (USDA, 2013). Table 1 lists the pack factors for each bin calculated using three methods: the WPACKING software, the RMA method, and the FSA-W method. The WPACKING software predicted pack factors based on the bin diameter, grain height, bin wall type, cone angle, moisture, TW, and bin bottom geometry, while the RMA method predicted pack factors based on varying bin diameter and TW, and the FSA-W method predicted pack factors based on bin diameter, bin shape, and TW. Detailed calculation procedures for the three methods are discussed by Boac et al. (2015). These pack factors were used to calculate grain mass from volume and TW measurements.

\section{Mass PREDICTED For INDIVIdUAL Bins}

Figure 1 shows the correlation between reported mass and the mass predicted by the three methods (WPACKING, RMA, and FSA-W) for all bins listed in table 1. For the measured bins, the WPACKING-predicted mass was very close to the reported mass, with a slope of 0.9998 for the entire dataset. The slope was 1.0206 for the RMA method and 0.9977 for the FSA-W method. Slopes closer to 1 indicate that the relationship between average predicted and reported mass is similar for different bin sizes. Data closer to the $1: 1$ line shown in figure 1 indicate that the predictions are closer to the reported values of mass.

Figure 2 shows the differences between predicted and reported mass for all three methods. The differences for WPACKING ranged from $-4.54 \%$ to $+4.53 \%$, with a median value of $-0.27 \%$ and an average absolute difference of $0.90 \%$. The median value of the differences does not indicate magnitude of differences but instead measures the overall bias of the method. Average absolute difference is defined as the average of the absolute values of the differences between predicted and reported mass, which measures the average magnitude of the deviations without the direction of differences that can be seen in the figure 2 . WPACKING underpredicted most bins; however, the two concrete bins were overpredicted by WPACKING compared to the reported masses. Thus, the wall and material parameters, such as $\mu$ and $k$, may have had an effect on overprediction or underprediction. Additional concrete bin data are needed to verify such a trend for corn with WPACKING.

The differences for the predictions from the RMA method (fig. 2) ranged from $-2.69 \%$ to $+4.97 \%$, with a median value of $+0.90 \%$ and an average absolute difference of $1.61 \%$. This range is similar to the differences for WPACKING, but the median value for the RMA method was positive instead of negative and much larger than it was for WPACKING $(+0.90 \%$ vs. $-0.27 \%)$. In addition, the RMA average absolute difference $(1.61 \%)$ was almost twice as large as for WPACKING (0.90\%). In figure $2 \mathrm{a}$, the majority of WPACKING data are close to $0 \%$ difference, with small underpredictions, for bin capacities less than $1500 \mathrm{t}$, whereas the differences between RMApredicted mass and reported mass are more variable than those for WPACKING, with a mix of overprediction and 


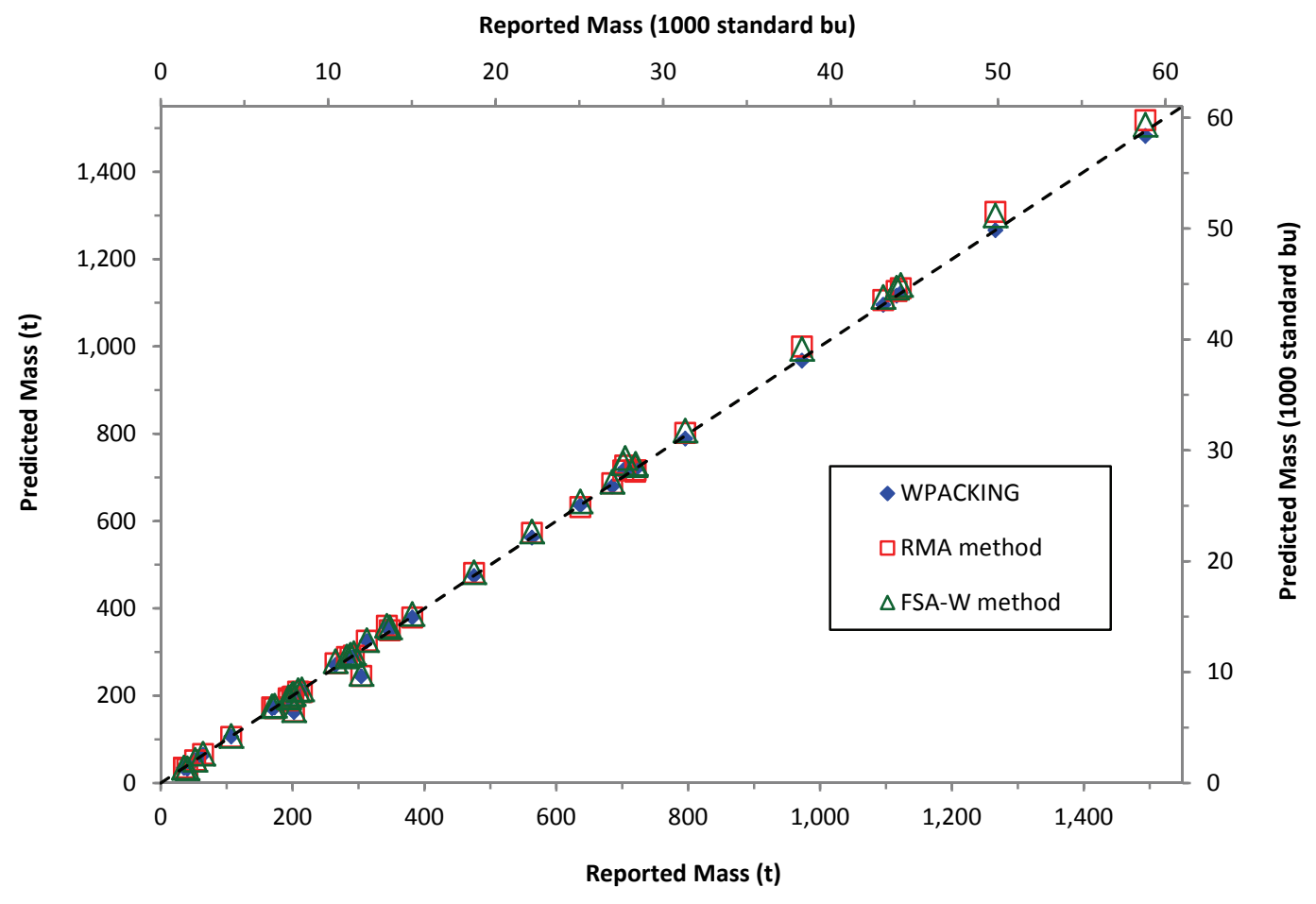

(a) Bins with capacity less than $1,500 \mathrm{t}(56,000 \mathrm{bu})$

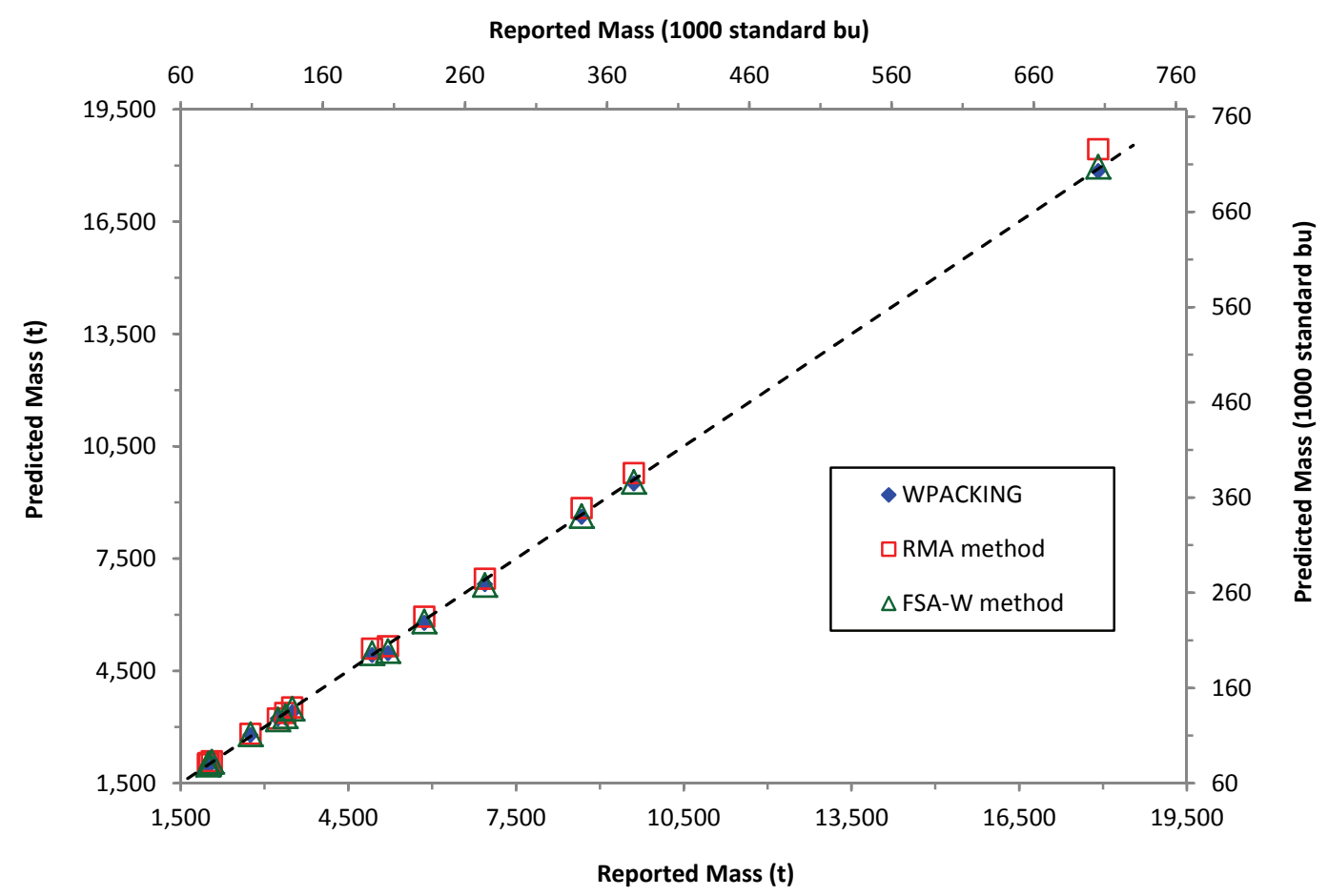

(b) Bins with capacity greater than $1,500 \mathrm{t}(56,000 \mathrm{bu})$

Figure 1. Reported mass and mass predicted by WPACKING, RMA method, and FSA-W method for individual bins, with 1:1 line.

underprediction. For bin capacities greater than $1,500 \mathrm{t}$ (fig. 2b), the RMA method often overpredicted the mass for the same bins that WPACKING underpredicted. The RMA method predicted more mass than WPACKING predicted for every bin larger than 1,500 t. The RMA method also overpredicted the two concrete bins by a greater amount than WPACKING overpredicted those bins.

The FSA-W method (fig. 2) overpredicted the mass for corn bins with less than $3000 \mathrm{t}$ capacity but underpredicted for the majority of bins with greater than $3000 \mathrm{t}$ capacity. The differences for the FSA-W method compared to reported mass ranged from $-3.33 \%$ to $+5.67 \%$ with a median 


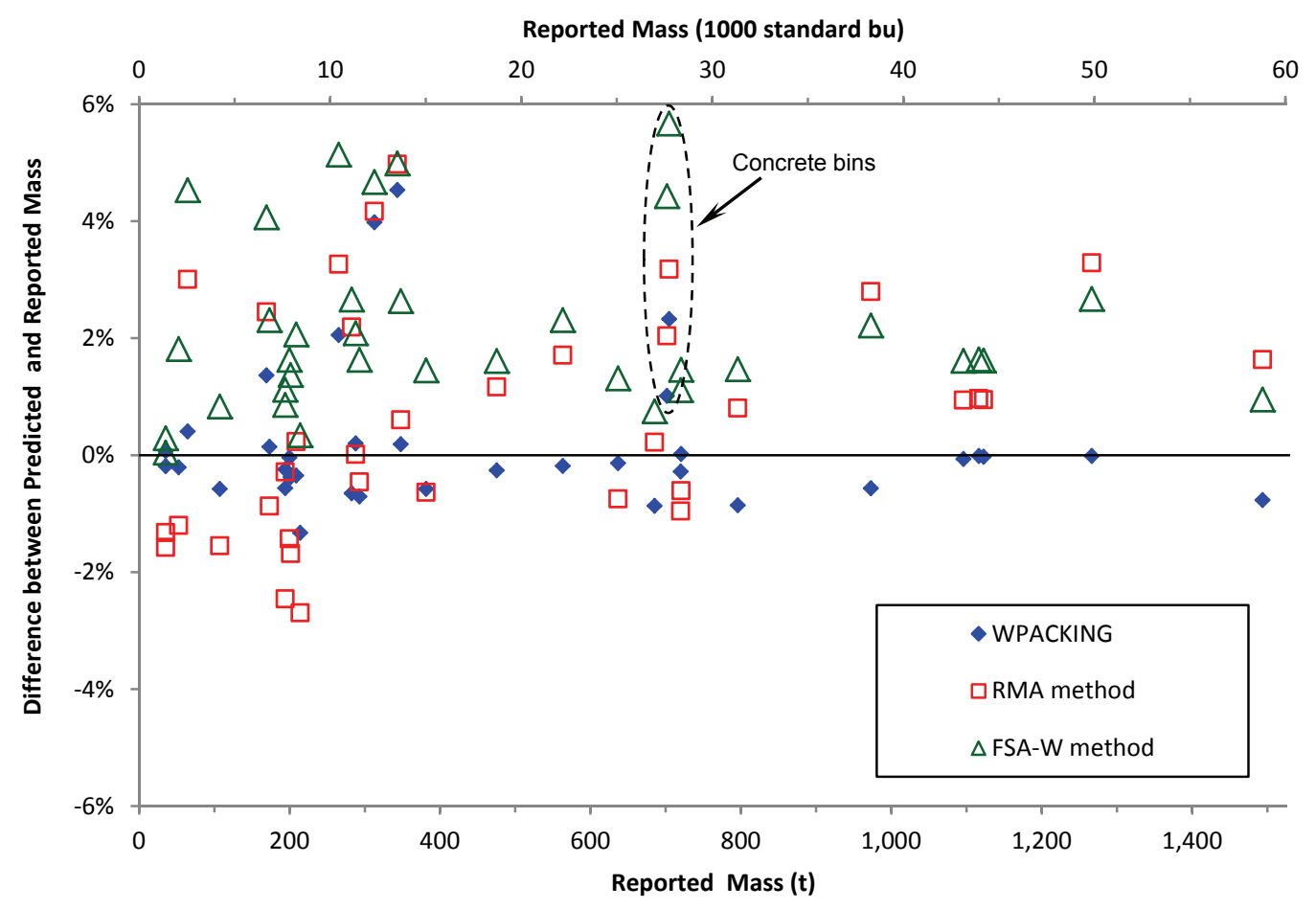

(a) Bins with capacity less than $1,500 \mathrm{t}(56,000 \mathrm{bu})$

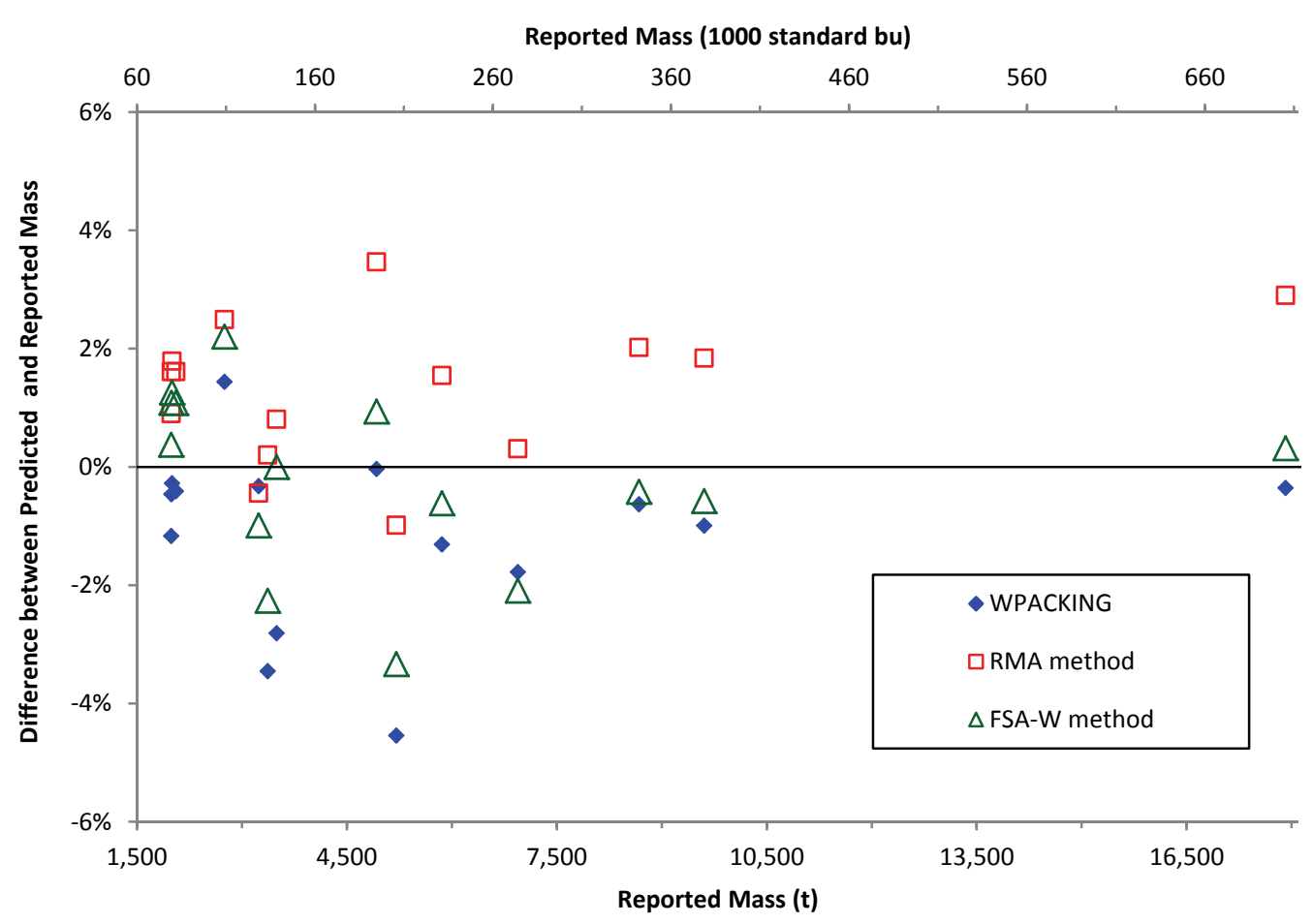

(b) Bins with capacity more than 1,500 t $(56,000$ bu)

Figure 2. Difference between predicted and reported mass for individual bins using the three methods. All bins were corrugated steel bins except for two concrete bins.

value of $+1.45 \%$ and an average absolute difference of $1.86 \%$. For small bins, this trend differed from the RMA method, where differences were more evenly distributed on either side of the zero percent difference line for bins smaller than 800 t. For large bins, larger than $3000 \mathrm{t}$, the
FSA-W method mostly underpredicted, while the RMA method mostly overpredicted. The FSA-W method predictions were all close to the WPACKING predictions for bins larger than $6000 \mathrm{t}$, but the FSA-W method mostly overpredicted bins smaller than $3000 \mathrm{t}$, while the WPACKING 
predictions were close to the zero difference line for bins smaller than 3000 t. The FSA-W method overpredicted the two concrete bins by a greater amount than either the RMA method or WPACKING. For the largest bins, about $5000 \mathrm{t}$ and larger, the FSA-W method generally had its smallest differences from the reported values, with only one of the five bins in that range showing more than $1 \%$ error $(2.1 \%)$. Additional data on large bins is needed to confirm this trend for the FSA-W method.

Comparing the three methods, the WPACKING differences were generally closer to the zero percent difference line, especially for bins of less than $1500 \mathrm{t}$ capacity. This is quantified by the average absolute difference for WPACKING $(0.90 \%)$, which is approximately half of that for either the RMA or FSA-W methods $(1.61 \%$ and $1.86 \%$, respectively). Paired t-tests indicated that the WPACKING average absolute difference was significantly different from those for the RMA and FSA-W methods ( $p<0.01$ in both cases), but the RMA and FSA-W differences were not significantly different from each other $(p>0.05)$. Furthermore, the WPACKING median value $(-0.27 \%)$, indicating the overall bias of the method, was much closer to the zero difference line than for either of the other two methods, which were $+0.90 \%$ and $+1.45 \%$. Mood's median test, using MINITAB software (v. 17), was run on each pair of medians and showed that the median values were significantly different $(p<0.05)$ for WPACKING vs. the RMA method and the FSA-W method, but medians were not significantly different for the RMA method vs. the FSA-W method ( $p>0.05)$. These results in- dicate that WPACKING predicted the mass for corn much better than the RMA and FSA-W methods.

The differences between predicted and reported mass were classified based on equivalent level height to bin diameter $(H / D)$ ratio and are plotted with respect to bin diameter in figures 3 through 5. As seen above for larger bins, WPACKING mostly underpredicted mass, especially when the bin diameter was greater than $15 \mathrm{~m}$ (about $50 \mathrm{ft}$ ) for all $\mathrm{H} / \mathrm{D}$ ratios. The WPACKING and FSA-W predictions showed greater differences with the 0.69 to $1.0 \mathrm{H} / \mathrm{D}$ ratios, but the RMA predictions had large, random distribution of differences between predicted and reported mass for all H/D ratios up to 2.0 (fig. 4). For bin diameters greater than $15 \mathrm{~m}$ $(50 \mathrm{ft}$ ), the FSA-W method (fig. 5) underpredicted for most bins with $\mathrm{H} / \mathrm{D}$ ratios up to 2.0 (two exceptions) and overpredicted for almost all $\mathrm{H} / \mathrm{D}$ ratios at diameters less than $15 \mathrm{~m}$ (one exception). In figure 3, only 13 of the 51 differences for WPACKING predictions are greater than $1 \%$ in magnitude, while 29 of 51 for the RMA method (fig. 4) and 33 of 51 for the FSA-W method (fig. 5) are greater than 1\%.

\section{Mass Predicted For Grouped Bins}

Table 2 lists groups of corn bins that were analyzed together because only the total mass of grain stored was known and not mass within individual bins. At these facilities, the total volume of each bin was measured, the predicted packing in each bin was calculated, and the total grain inventory was determined by summing the predicted mass of all the bins. This was compared to the total mass stored within the

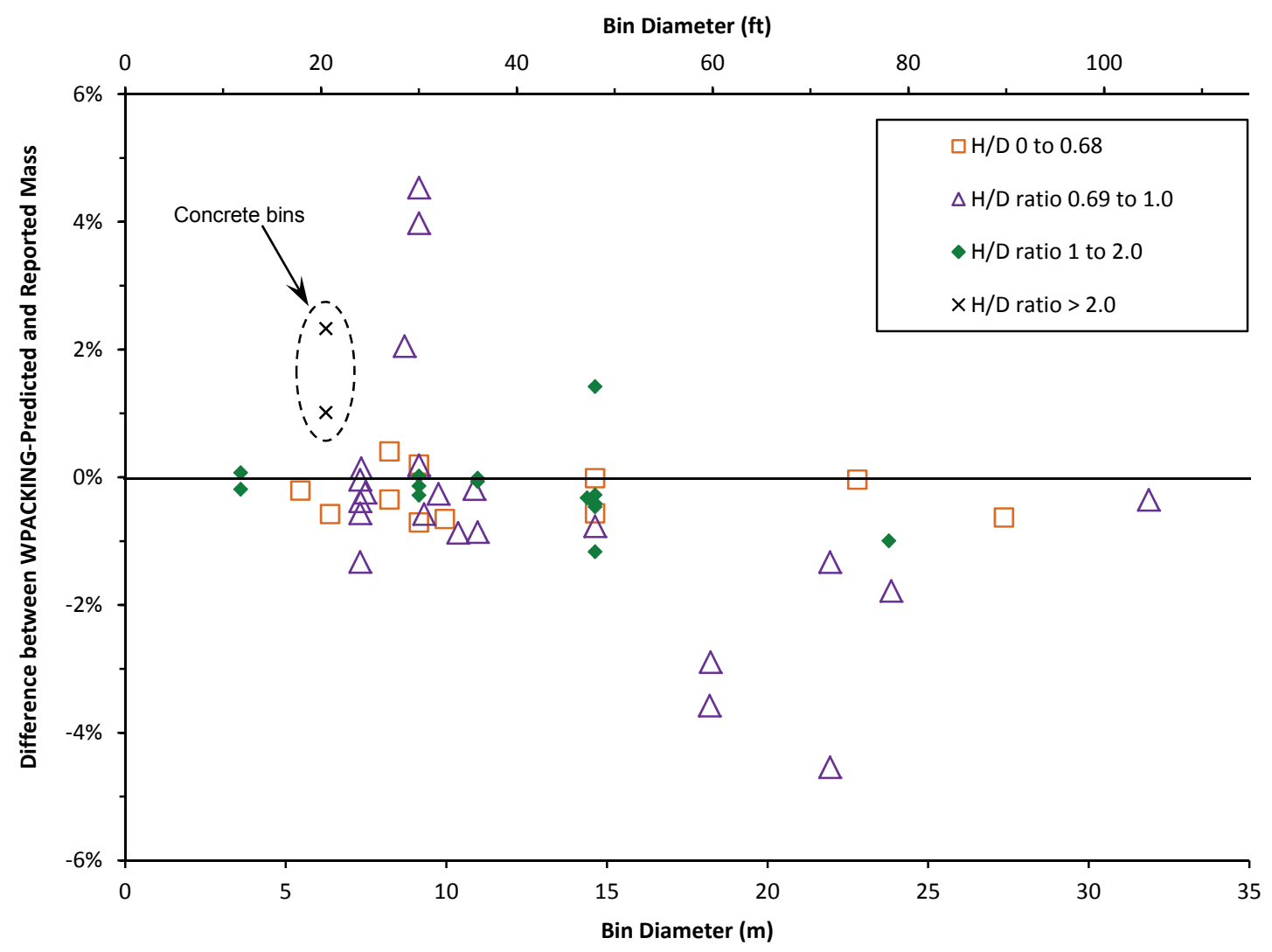

Figure 3. Difference between predicted and reported mass with respect to bin diameter and classified based on grain height/diameter (H/D) ratio for the WPACKING model. 


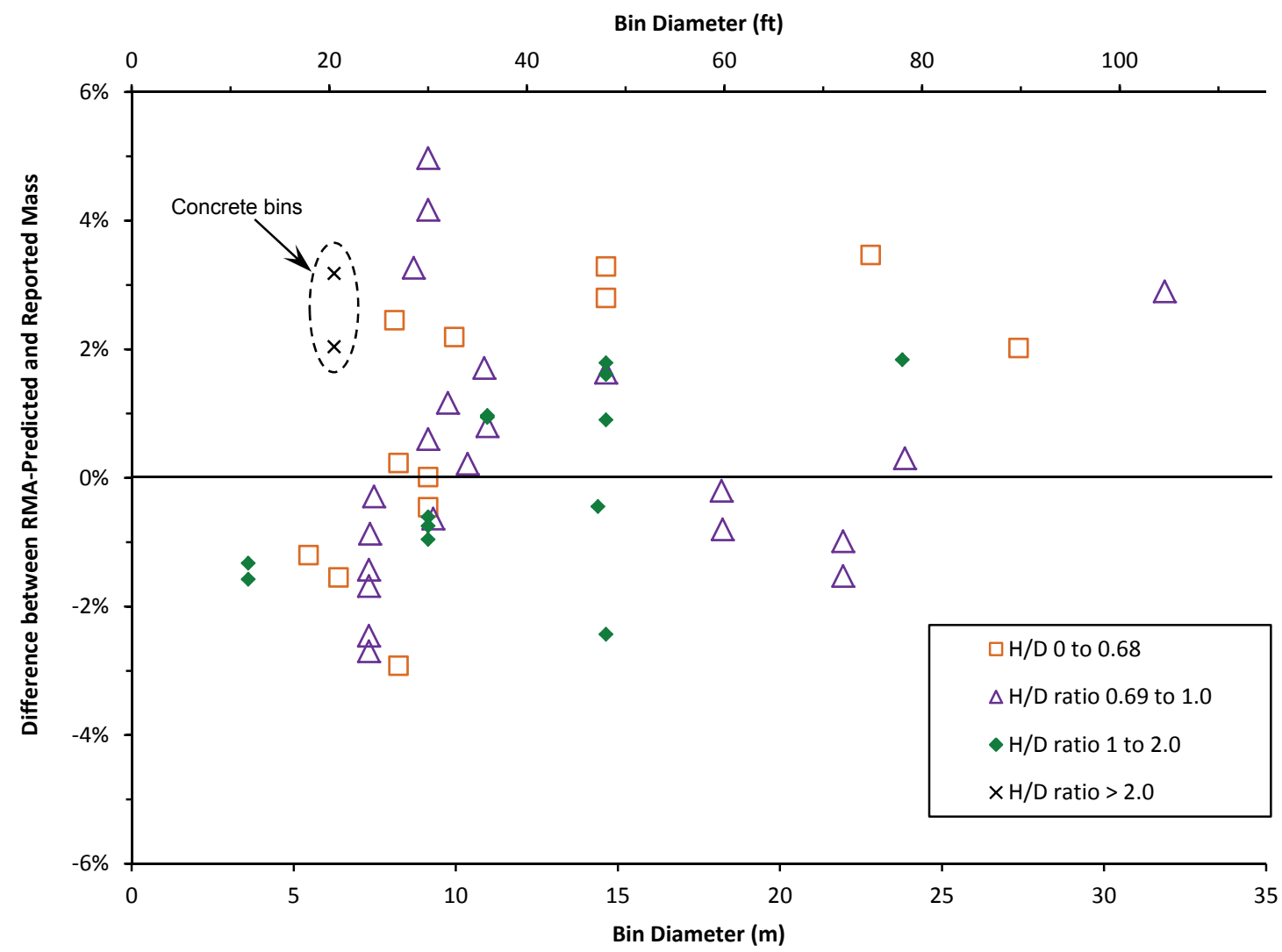

Figure 4. Difference between predicted and reported mass with respect to bin diameter and classified based on grain height/diameter (H/D) ratio for the RMA method.

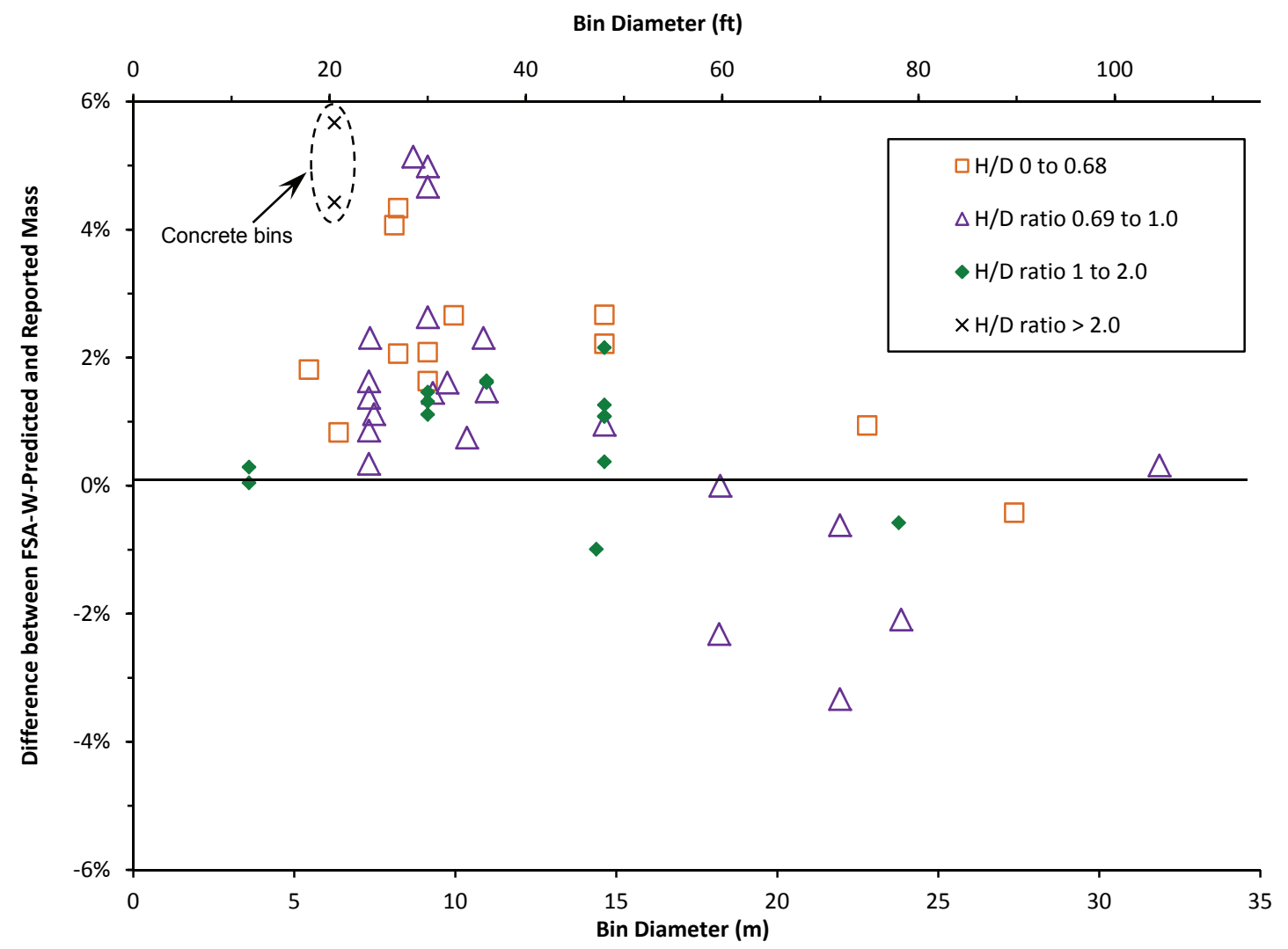

Figure 5. Difference between predicted and reported mass with respect to bin diameter and classified based on grain height/diameter (H/D) ratio for the FSA-W method. 
Table 2. Summary of bin geometry and compaction factors for commercial corn bins for grouped reported scale values based on location. ${ }^{\text {[a] }}$

\begin{tabular}{|c|c|c|c|c|c|c|c|c|c|c|}
\hline \multirow{2}{*}{$\begin{array}{l}\text { No. of } \\
\text { Bins in } \\
\text { Group }\end{array}$} & \multirow[b]{2}{*}{ Location } & \multirow[b]{2}{*}{ Bin Type } & \multirow{2}{*}{$\begin{array}{c}\text { Diameter } \\
\text { Range } \\
\text { (m) }\end{array}$} & \multirow{2}{*}{$\begin{array}{c}\text { Eave } \\
\text { Height } \\
\text { Range } \\
\text { (m) }\end{array}$} & \multirow{2}{*}{$\begin{array}{c}\text { Equivalent } \\
\text { Level Height } \\
\text { Range } \\
\text { (m) }\end{array}$} & \multirow{2}{*}{$\begin{array}{c}\text { Average } \\
\text { TW } \\
\left(\mathrm{kg} \mathrm{m}^{-3}\right)\end{array}$} & \multirow{2}{*}{$\begin{array}{c}\text { Average } \\
\text { MC } \\
\text { (\% w.b.) }\end{array}$} & \multicolumn{3}{|c|}{$\begin{array}{c}\text { Apparent Pack Factor }{ }^{[\mathrm{b}]} \\
\text { (unitless) }\end{array}$} \\
\hline & & & & & & & & WPACKING & RMA & FSA-W \\
\hline 1 & Russellville, Ky. ${ }^{[\mathrm{c}]}$ & Corrugated steel & 18.2 & 18.0 & $52-54$ & 754.0 & 14.5 & 1.112 & 1.110 & 1.143 \\
\hline 4 & Versailles, Ky. & Corrugated steel & $8.2-10.9$ & $6.1-9.4$ & $1.2-4.11$ & 749.4 & 14.0 & 1.064 & 1.100 & 1.094 \\
\hline 2 & Versailles, Ky. & Corrugated steel & $8.2-10.9$ & $7.6-9.4$ & $1.0-7.3$ & 736.1 & 13.4 & 1.044 & 1.077 & 1.076 \\
\hline 2 & Versailles, Ky. & Corrugated steel & $8.2-10.9$ & $7.6-9.4$ & $2.3-7.9$ & 734.2 & 13.0 & 1.043 & 1.076 & 1.076 \\
\hline 1 & Russellville, Ky. ${ }^{[\mathrm{c}]}$ & Corrugated steel & 27.3 & 27.7 & $15.6-19.1$ & 754.0 & 14.5 & 1.126 & 1.110 & 1.143 \\
\hline 1 & Russellville, Ky. ${ }^{[\mathrm{c}]}$ & Corrugated steel & 27.3 & 27.7 & $11.2-16$ & 757.4 & 14.1 & 1.117 & 1.119 & 1.153 \\
\hline 3 & Midland, Mich. & Corrugated steel & $4.5-14.6$ & $7.1-14.2$ & $7.8-9.8$ & 741.7 & 14.7 & 1.069 & 1.094 & 1.102 \\
\hline 1 & Russellville, Ky. ${ }^{[\mathrm{c}]}$ & Corrugated steel & 27.4 & 27.7 & $19.1-25.7$ & 754.2 & 14.5 & 1.122 & 1.110 & 1.143 \\
\hline 4 & Hodgenville, Ky. & Corrugated steel & $7.3-14.6$ & $7.7-12.2$ & $5.5-13.9$ & 762.4 & 14.0 & 1.099 & 1.118 & 1.122 \\
\hline 1 & Russellville, Ky. ${ }^{[\mathrm{c}]}$ & Corrugated steel & 27.7 & 27.7 & $16-25.7$ & 754.2 & 14.1 & 1.123 & 1.110 & 1.143 \\
\hline 13 & Dunkirk, Ind. & Concrete & $3.4-19.8$ & $2.6-30.2$ & $2.6-30.2$ & 735.3 & 14.3 & 1.071 & 1.084 & 1.078 \\
\hline 3 & Brown City, Mich. & Corrugated steel & $7.3-21.8$ & $14.5-22.3$ & $7.3-21.2$ & 750.3 & 14.9 & 1.094 & 1.102 & 1.125 \\
\hline 4 & Hopkinsville, Ky. & Corrugated steel & 31.8 & $24.4-27.6$ & $5.3-27.8$ & 773.5 & 13.7 & 1.158 & 1.168 & 1.203 \\
\hline 3 & Hopkinsville, Ky. & Corrugated steel & 31.8 & $24.4-27.7$ & $0.7-23.4$ & 773.5 & 13.7 & 1.121 & 1.122 & 1.156 \\
\hline 4 & Hopkinsville, Ky. & Corrugated steel & 31.8 & $24.4-27.6$ & $8.9-27.8$ & 773.5 & 13.7 & 1.137 & 1.134 & 1.168 \\
\hline 3 & Hopkinsville, Ky. & Corrugated steel & $18.2-31.7$ & $19.5-27.5$ & $5.3-26.7$ & 773.5 & 13.7 & 1.119 & 1.122 & 1.156 \\
\hline 4 & Hopkinsville, Ky. & Corrugated steel & 31.8 & $24.4-27.6$ & $0.7-28.6$ & 773.5 & 13.7 & 1.137 & 1.142 & 1.177 \\
\hline 4 & Hopkinsville, Ky. & Corrugated steel & 32.8 & $24.4-27.7$ & $5.3-28.6$ & 773.5 & 13.7 & 1.146 & 1.149 & 1.183 \\
\hline 4 & Hopkinsville, Ky. & Corrugated steel & $18.2-31.7$ & $19.5-27.5$ & $11.14-27.8$ & 773.5 & 13.7 & 1.133 & 1.139 & 1.173 \\
\hline 4 & Hopkinsville, Ky. & Corrugated steel & 31.8 & $24.4-27.6$ & $0.7-27.8$ & 773.5 & 13.7 & 1.137 & 1.139 & 1.173 \\
\hline 4 & Hopkinsville, Ky. & Corrugated steel & $18.2-31.8$ & $19.5-27.6$ & $11.1-28.6$ & 773.5 & 13.7 & 1.135 & 1.137 & 1.171 \\
\hline
\end{tabular}

a] $\mathrm{TW}=$ test weight, usually measured according to FGIS guidelines in $\mathrm{lbs} \mathrm{bu}^{-1}$, and $\mathrm{MC}=$ moisture content.

[b] Apparent pack factor is total predicted mass for a group of bins divided by the total reported mass of that group.

[c] Single bin that was measured multiple times (after multiple grain transfers) with one reported mass compared after all measurements.

facility based on scale data provided by the cooperator. $\mathrm{Nu}-$ merous issues limited the ability to determine the corn mass in individual bins. Many facilities do not track the quantity of corn going into each bin, but the total quantity of each commodity is known for the whole facility. This prevented analysis of bins individually but still allowed determination of differences on a facility basis. In addition, some of the data were collected from a subset of bins at facilities where a trainload of corn was shipped. The bins were measured prior to loading the train and after loading the train. This allowed for prediction error to be calculated based on the before and after measurements.

Figure 6 summarizes the reported mass and the mass predicted using the WPACKING, RMA, and FSA-W methods for the bin groups using facility totals. Deviations from the 1:1 line were often greater for these groups (fig. 6) than for individual bins (fig. 1). The median difference between predicted and reported mass was $-2.9 \%,-0.24 \%$, and $-2.2 \%$ for the WPACKING, RMA, and FSA-W methods, respectively. The average absolute difference for the WPACKING, RMA, and FSA-W methods was $4.8 \%, 4.3 \%$, and $4.4 \%$, respectively.

Figure 7 shows the differences between predicted and reported mass over the range of facilities measured. The RMA method usually predicted greater mass than the other two methods, averaging $2.0 \%$ higher than the FSA-W method and $2.8 \%$ higher than WPACKING. The values of predicted mass from WPACKING and the FSA-W method were nearly the same for larger values of reported mass, similar to the results for large individual bins. The FSA-W method predicted more mass than WPACKING for 8 of the 11 cases with less than 10,000 t reported mass at the facility, which was similar to the trend for individual bins of less than about 6,000 t (fig. 2). The greater errors observed with the grouped bins relative to the individual bins was expected. The largest error in the measurements is in charac- terizing the grain surface. For the grouped bins, multiple surface measurements (measured using the same laser device technique discussed above) were required, both because multiple bins entail multiple surfaces and because each bin in a group was often measured twice, once before and once after grain was moved. However, for individual bins, the total mass in the bin was reported for the depth measured, and only one grain surface measurement was required to calculate volume for each case.

\section{Conclusions}

Commercial and on-farm bins across the U.S. containing shelled corn were measured, and grain mass in each bin or on a facility basis was calculated using three methods: the WPACKING model, the RMA method, and the FSA-W method. Calculated mass was compared to scale data for each bin or on a facility basis. The WPACKING model is based on the differential form of Janssen's equation with the required density-pressure relationships measured in the laboratory, while the other two methods used purely empirical relationships to obtain pack factors. Most of the bins were constructed of corrugated steel, while only a few were concrete. The major conclusions of this study are the following:

- The average absolute difference between predicted mass and reported mass of individual bins was the lowest at $0.90 \%$ (-4.54\% maximum underprediction, $+4.53 \%$ maximum overprediction) for WPACKING, higher at $1.61 \%$ (-2.69\% maximum underprediction, $+4.97 \%$ maximum overprediction) for the RMA method, and highest at $1.86 \%$ (-3.33\% maximum underprediction, $+5.67 \%$ maximum overprediction) for the FSA-W method.

- WPACKING exhibited much fewer predictions (13 of 51 ) with more than $1 \%$ difference from the report- 


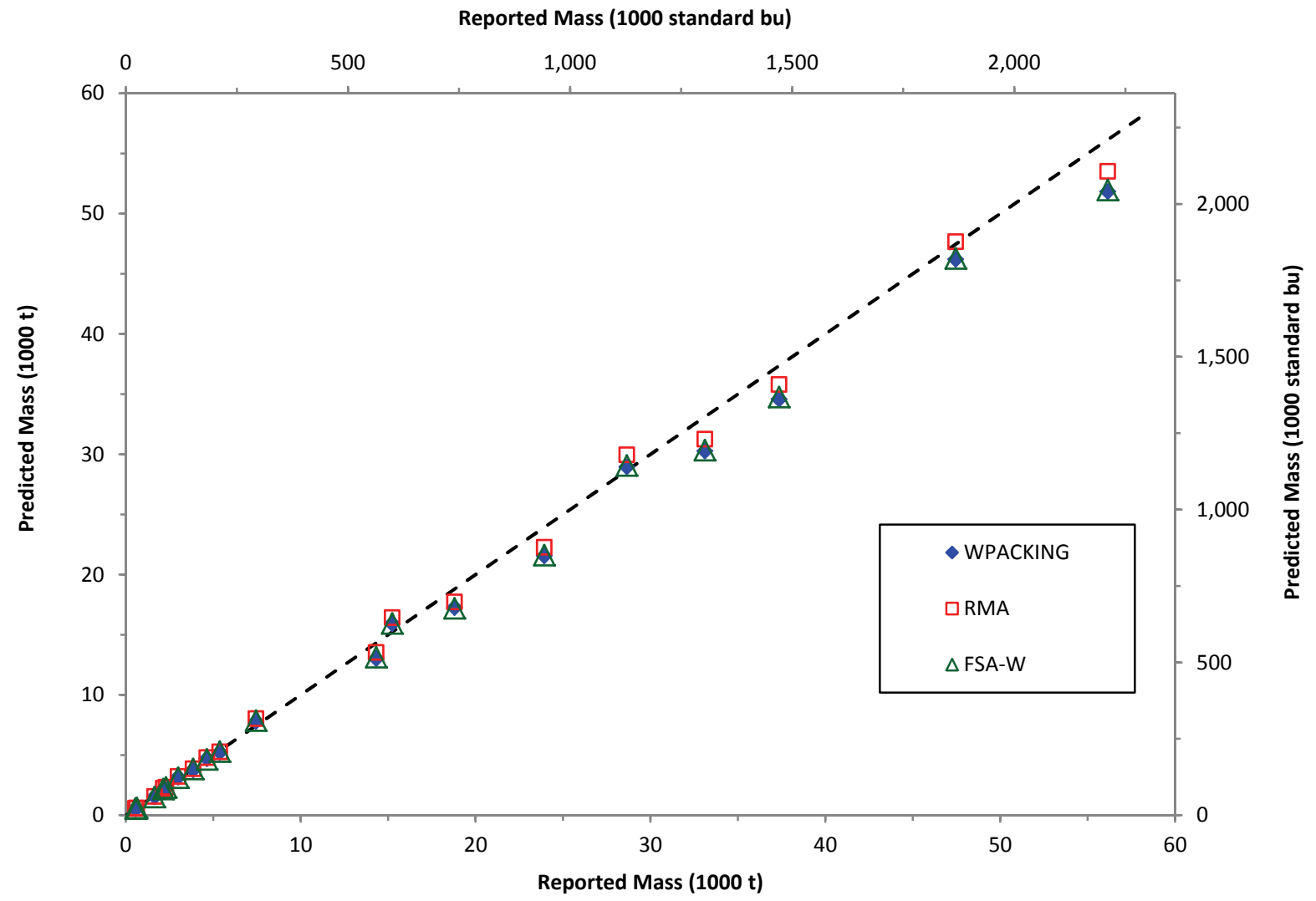

Figure 6. Reported mass and predicted mass based on facility totals using WPACKING, RMA method, and FSA-W method with 1:1 line.

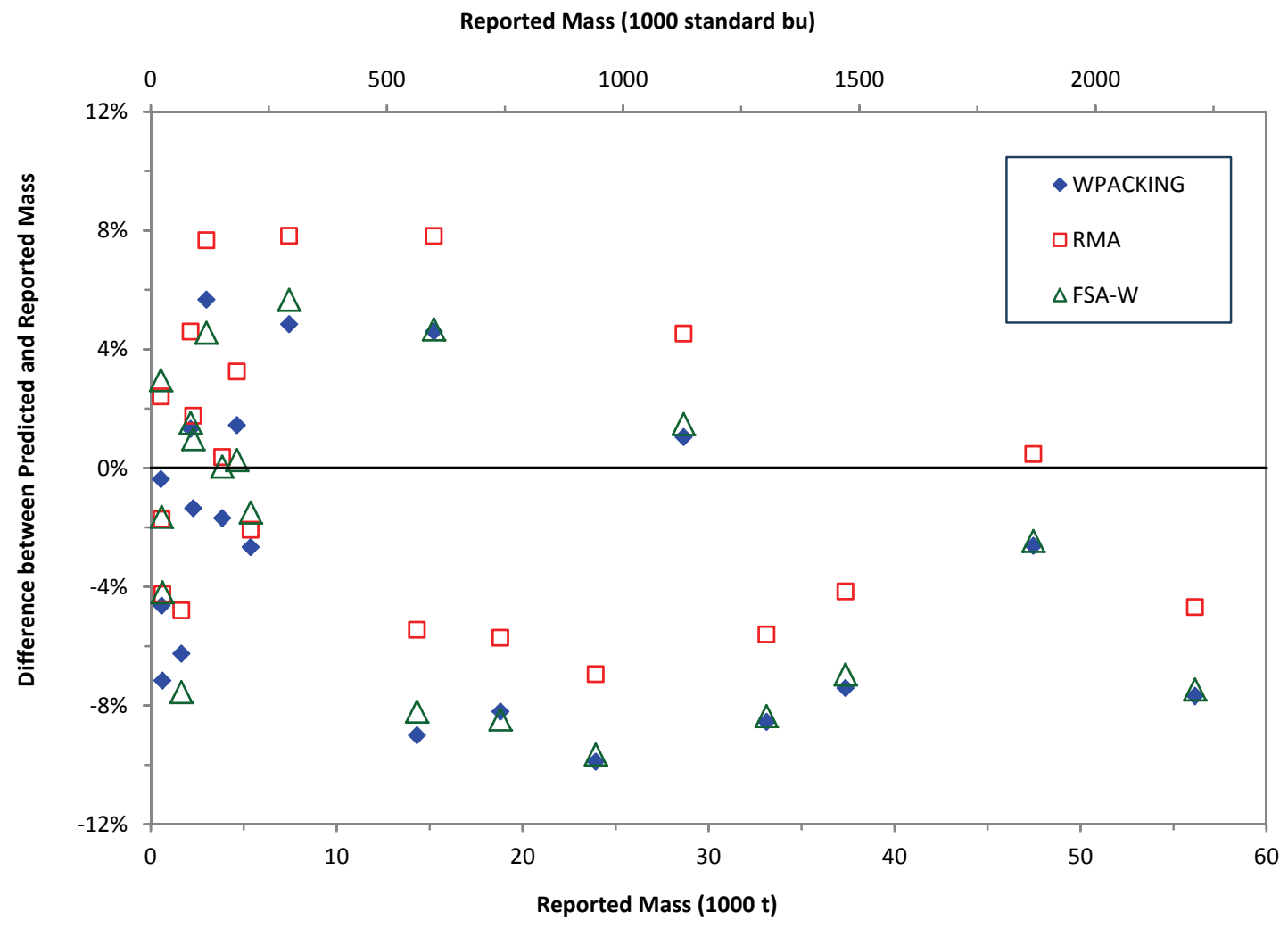

Figure 7. Percent error with the three methods for grouped corn bins. 
ed mass than both the RMA method (29 of 51) and FSA-W method (33 of 51).

- WPACKING mostly underpredicted mass, with the exceptions being for smaller bins (less than $10 \mathrm{~m}$ diameter and less than $800 \mathrm{t}$ reported mass, except one case at $2750 \mathrm{t}$ ), irrespective of H/D ratios up to 2.0.

- The RMA method overpredicted almost all bins $(87 \%$ of the bins) larger than $800 \mathrm{t}$ reported mass and had mostly random differences $(50 \%$ of the bins above and below zero difference line) for bins smaller than $800 \mathrm{t}$.

- The FSA-W method overpredicted all bins with less than $1500 \mathrm{t}$ reported mass, mostly underpredicted the mass in larger bins (larger than $1500 \mathrm{t}$ ), and exhibited mostly small differences from reported mass with the largest measured bins (5000 $t$ and larger).

- With grouped bins, the average absolute errors of the WPACKING, RMA, and FSA-W methods were $4.8 \%, 4.3 \%$, and $4.4 \%$, respectively.

These results compare the currently used methods for pack factor prediction in the U.S., showing their characteristics and limitations and indicating that the WPACKING model predicted more accurate pack factors for corn than the other two methods. In addition, WPACKING is amenable to updating with additional laboratory data and fine tuning of $\mu$ and $k$ input values (eq. 2) based on these results, which could further improve the predictions by the WPACKING model.

\section{ACKNOWLEDGEMENTS}

The assistance provided by Dennis Tilley (USDA-ARS CGAHR), Dr. Ekramul Haque (KSU), Kevin Hamm (KSU), Chris Weston (USDA-ARS CGAHR), and Howell Gonzales (KSU) in conducting the field tests is highly appreciated. We also appreciate the assistance of Dr. Tom Herald (USDA-ARS CGAHR), Brian Linin and Richard Bauman (Frontier Ag, Inc.), Marvin Schlatter (ADM), Dr. Danny Rogers, (KSU), Greg McClure (Riley County Extension Office), Mike Schulte (Oklahoma Wheat Commission), Ben Boerner (Texas Grain and Feed Association), Ned Bergman and Steve Becker (Farm Service Agency), Dr. Charles R. Hurburgh Jr. (Iowa State University), and other extension specialists, university professors, and grain researchers in locating cooperators. Finally, we thank our elevator-cooperators: Joey Meibergen and Montie Walton of W.B. Johnston Terminal Elevator (Enid, Okla.), Joshua Dechant of Frontier Ag, Inc. (Goodland and Wakeeney, Kan.), Steve Young of Grainland Cooperative (Holyoke, Colo.), Lindsey Bowers and Steven Craig of United Agricultural Coop (El Campo, Tex.), Scott Day and Jimmie Bradley of Attebury Grain LLC (Amarillo, Tex.), and Gary Holcomb and Dave Hoffman of Sunray Coop (Sunray, Tex.).

\section{REFERENCES}

Amundson, L. R. (1945). Determination of band stresses and lateral wheat pressures of a cylindrical grain bin. Agric. Eng., 26(8), 321-324.

ASABE. (2010). EP413.2: Procedure for establishing volumetric capacities of cylindrical bins. St. Joseph, Mich.: ASABE.

Bates, E. N. (1925). Estimating the quantity of grain in bins. Misc. Circular No. 41. Washington, D.C.: USDA.
Boac, J., Bhadra, R., Casada, M. E., Thompson, S. A., Turner, A. P., Montross, M. D., McNeill, S. G., \& Maghirang, R. G. (2015). Stored grain pack factors for wheat: Comparison of three methods to field measurements. Trans. ASABE (in review).

Chang, C. S., Converse, H. H., \& Martin, C. R. (1983). Bulk properties of grain as affect by self-propelled rotational type grain spreader. Trans. ASAE, 26(5), 1543-1550. http://dx.doi.org/10.13031/2013.34167.

Clower, R. E., Ross, I. J., \& White, G. M. (1973). Properties of compressible granular materials as related to forces in bulk storage structures. Trans. ASAE, 16(3), 478-481. http://dx.doi.org/10.13031/2013.37547.

Janssen, H. A. (1895). Versuche über getreidedruck in silozellen. Zeitschrift d. Vereines Deutscher Ingenieure, 39(35), 1045-1049.

Loewer Jr., O. J., Ross, I. J., Kratzer, D. D., \& Walker, J. N. (1977). Properties of ground shelled corn as related to forces in bulk storage structures. Trans. ASAE, 20(1), 155-156. http://dx.doi.org/10.13031/2013.35512.

Lorenzen, R. T. (1957). Effect of moisture content on mechanical properties of small grains. MS thesis. Davis, Cal.: University of California-Davis.

McNeill, S. G., Montross, M. D., Thompson, S. A., Ross, I. J., \& Bridges, T. C. (2008). Technical note: Packing factors of feed products in storage structures. Appl. Eng. Agric., 24(5), 625-630. $\mathrm{http} / / / \mathrm{dx}$.doi.org/10.13031/2013.25260.

MWPS. (1997). Grain Drying, Handling, and Storage Handbook (2nd ed.). MWPS-13. Ames, Iowa: Midwest Plan Service.

Mohsenin, N. N. (1986). Physical Properties of Plant and Animal Materials (2nd ed.). New York, N.Y.: Gordon and Breach Science.

Molenda, M., Horabik, J., \& Ross, I. J. (1993). Loads in model grain bins as affected by filling methods. Trans. ASAE, 36(3), 915-919. http://dx.doi.org/10.13031/2013.28416.

Moysey, E. B. (1984). The effect of grain spreaders on grain friction and bin wall pressures. J. Agric. Eng. Res., 30, 149-156.

Smalley, I. J. (1970). Variations on the particle packing theme of Graton and Fraser. Powder Tech., 4(2), 97-101.

Stahl, B. M. (1950). Grain bin requirements. Circular No. 835. Washington, D.C.: USDA.

Stephens, L. E., \& Foster, G. H. (1976). Grain bulk properties as affected by mechanical grain spreader. Trans. ASAE, 19(2), 354358. http://dx.doi.org/10.13031/2013.36027.

Thompson, S. A., McNeill, S. G., Ross, I. J., \& Bridges, T. C. (1987). Pack factors of whole grains in storage structures. Appl. Eng. Agric., 3(2), 215-221. http://dx.doi.org/10.13031/2013.26677.

Thompson, S. A., McNeill, S. G., Ross, I. J., \& Bridges, T. C. (1990). Computer model for predicting the packing factors of whole grains in flat storage structures. Appl. Eng. Agric., 6(4), 465-470. http://dx.doi.org/10.13031/2013.26415.

Thompson, S. A., Schwab, C. V., \& Ross, I. J. (1991). Calibration of a model for packing whole grains. Appl. Eng. Agric., 7(4), 450-456. http://dx.doi.org/10.13031/2013.26244.

USDA. (2008). Warehouse Examiner's Handbook: Grain Pack Data. Washington, D.C.: USDA Farm Service Agency, Commodity Services, Procurement and Warehouse Branch.

USDA. (2011). Corn Loss Adjustment Standards Handbook. Directive No. 25080. Washington, D.C.: USDA Risk Management Agency. Retrieved from www.rma.usda.gov/data/25000/2013.html.

USDA. (2012). Loss Adjustment Manual (LAM) Standards Handbook. Directive No. 25010-1H. Washington, D.C.: USDA Risk Management Agency. Retrieved from www.rma.usda.gov/data/25000/2012.html.

USDA. (2013). Grain Inspection Handbook: Book II. Grain Grading Procedures. Washington, D.C.: USDA Grain Inspection, Packers, and Stockyards Administration. 